\title{
Spawning of the basket star Astrophyton muricatum in the Bahamas
}
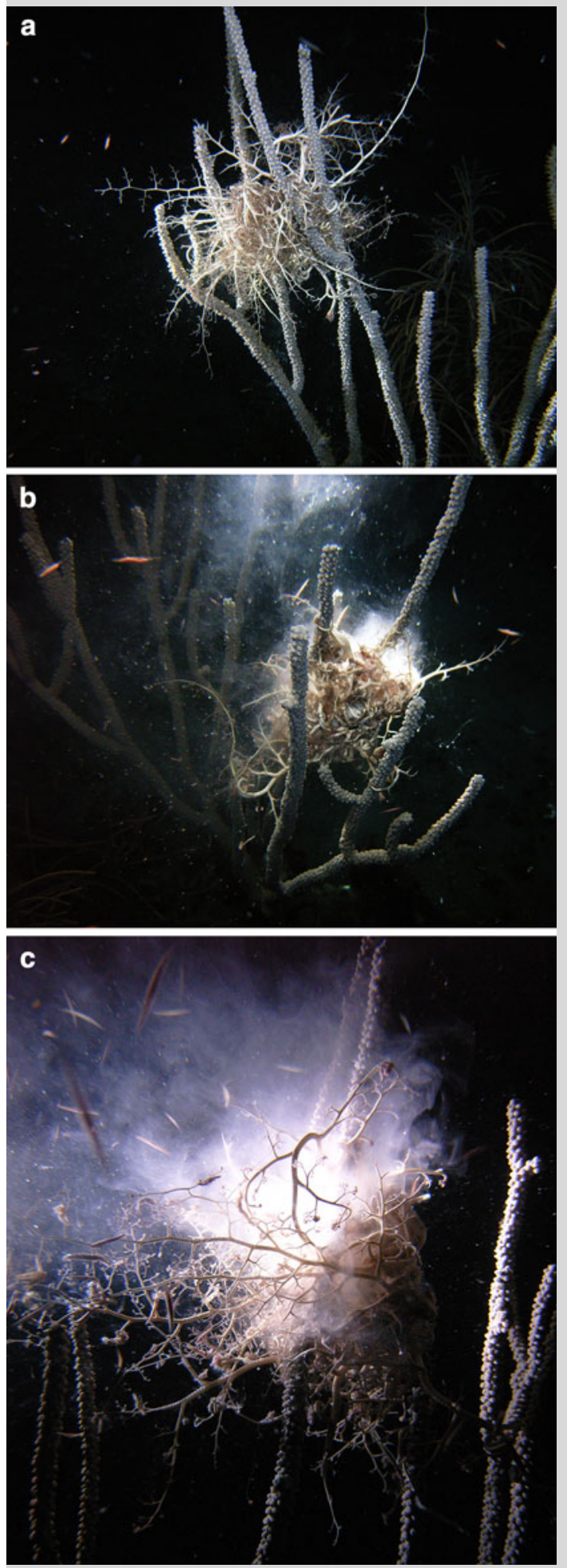

4 Fig. 1 Astrophyton muricatum spawning, Sweetings Cay, Bahamas. a Dorsal view of basket star at the beginning of gamete release. b Same individual as in a, ventral view, 1 min later. c Same individual as in a and $\mathbf{b}$, side view, 2 min later

Astrophyton muricatum is a nocturnal ophiuroid (order Euryalida) found in reef and seagrass habitats in the western Atlantic and Caribbean (Hendler et al. 1995). On the night of 3 July 2010, we observed broadcast spawning of a single individual of $A$. muricatum perched, approximately $1 \mathrm{~m}$ above the substratum, on a gorgonian (Eunicea sp.) on a patch reef $(17 \mathrm{~m})$ off Sweetings Cay $\left(26^{\circ} 33.777^{\prime \prime} \mathrm{N}, 77^{\circ} 52.890^{\prime \prime} \mathrm{W}\right)$, Grand Bahama Island, Bahamas. When encountered (20:15 h), the individual was in a typical feeding position with arm branches extended and was releasing a cloud of gametes that was dispersed by prevailing currents (Fig. 1a, b, c). While spawning, the individual's arms coiled toward the disk when directly illuminated (Fig. 1b), as is typical of this species (Hendler et al. 1995); arms extended after the light beam was shifted aside, and terminal tendrils ensnared epitokes of syllid polychaetes that were swimming toward the illumination (Fig. 1c). Spawning ceased 5 min after initial observations, and the individual remained in a feeding position. Four individuals of $A$. muricatum with extended arms were found within $20 \mathrm{~m}$ of the spawning individual during and immediately after this event.

These individuals coiled their arms when directly illuminated, but were not observed to spawn. This event occurred during a half-moon phase and one week after the full moon; water temperature was $29.5^{\circ} \mathrm{C}$. Wolfe (1978) found females of A. muricatum to have large eggs throughout the year, however, little is known about the timing of their spawning. This is the first observation of which we are aware on the spawning of Euryalida in the field (Hendler 1991).

Acknowledgments We thank Joseph R Pawlik for inviting us to participate in the research during which this event was observed and Gordon Hendler for helpful comments. JRP was supported by a National Science Foundation grant (OCE-1029515).

\section{References}

Hendler G (1991) Echinodermata: Ophiuroidea. In: Giese AC, Pearse JS (eds) Reproduction of marine invertebrates, vol VI. Blackwell Scientific, The Boxwood Press, Pacific Grove, CA, pp 355-511

Hendler G, Miller JE, Pawson DL, Kier PM (1995) Sea stars, sea urchins and allies. Echinoderms of Florida and the Caribbean. Smithsonian Institution Press, Washington, DC

Wolfe TJ (1978) Aspects of the biology of Astrophyton muricatum (Lamarck, 1816) (Ophiuroidea: Gorgonocephalidae). MS thesis, University of Puerto Rico

\section{S. E. McMurray $(\bowtie) \cdot$ J. Vicente $\cdot$ K. E. Jabanoski $\cdot$ T. B. Lewis}

Department of Biology and Marine Biology, University of North Carolina Wilmington, 601 South College Road, Wilmington, NC 28403, USA e-mail: sem6678@uncw.edu 